\title{
Operationalizing Learning from Rare Events: Framework for Middle Humanitarian Operations Managers
}

\author{
Amr Mahfouz \\ Technological University Dublin, amr.mahfouz@tudublin.ie \\ Ashraf labib \\ University of Portsmouth, ashraf.labib@port.ac.uk \\ Sara Hadleigh-Dunn \\ University of Portsmouth
}

See next page for additional authors

Follow this and additional works at: https://arrow.tudublin.ie/suppresart

Part of the Business Administration, Management, and Operations Commons

\section{Recommended Citation}

Mahfouz, A. et al (2019) Operationalizing Learning from Rare Events: Framework for Middle Humanitarian Operations Managers, Production and Operations Management,Vol.28, Issue9,Sept. 2019, pp. 2323-2337. DOI:10.1111/poms.13054

This Article is brought to you for free and open access by the Supply Chain Management at ARROW@TU Dublin. It has been accepted for inclusion in Articles by an authorized administrator of ARROW@TU Dublin. For more information, please contact arrow.admin@tudublin.ie, aisling.coyne@tudublin.ie,gerard.connolly@tudublin.ie.

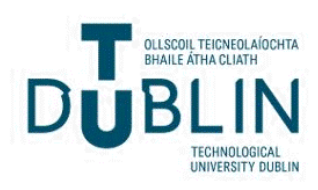


Authors

Amr Mahfouz, Ashraf labib, Sara Hadleigh-Dunn, and Marco Gentile

This article is available at ARROW@TU Dublin: https://arrow.tudublin.ie/suppresart/1 


\title{
Operationalizing Learning from Rare Events: Framework for Middle Humanitarian Operations Managers
}

\author{
Ashraf Labib*, Sara Hadleigh-Dunn \\ Portsmouth Business School, University of Portsmouth, Portsmouth PO1 2UP, UK, ashraf.labib@port.ac.uk, sara.hadleigh- \\ dunn@port.ac.uk
}

Amr Mahfouz

Dublin Institute of Technology, Dublin 2, D08 X622, Ireland, amr.mahfouz@dit.ie

Marco Gentile

Portsmouth Business School, University of Portsmouth, Portsmouth PO1 2UP, UK, up832182@myport.ac.uk

\begin{abstract}
$\mathrm{T}$ he purpose of this paper is to investigate the learning from rare events and the knowledge management process involved, which presents a significant challenge to many organizations. This is primarily attributed to the inability to interpret these events in a systematic and "rich" manner, which this paper seeks to address. We start by summarizing the relevant literature on humanitarian operations management (HOM), outlining the evolution of the socio-technical disaster lifecycle and its relationship with humanitarian operations, using a supply chain resilience theoretical lens. We then outline theories of organizational learning (and unlearning) from disasters and the impact on humanitarian operations. Subsequently, we theorize the role of middle managers in humanitarian operations, which is the main focus of our paper. The main methodology incorporates a hybrid of two techniques for root cause analysis, applied to two related case studies. The cases were specifically selected as, despite occurring twenty years apart, there are many similarities in the chain of causation and supporting factors, potentially suggesting that adequate learning from experience and failures is not occurring. This provides a novel learning experience within the HOM paradigm. Hence, the proposed approach is based on a multilevel structure that facilitates the operationalization of learning from rare events in humanitarian operations. The results show that we are able to provide an environment for multiple interpretations and effective learning, with emphasis on middle managers within a humanitarian operations and crisis/disaster management context.
\end{abstract}

Key words: risk management; operations management; learning from disasters; middle managers; humanitarian operations management

History: Received: July 2018; Accepted: April 2019 by Martin Starr and Sunil Gupta, after 2 revisions.

\section{Introduction}

A disaster may be considered as a "black swan," a term coined by Taleb (2010) to describe an event which has the three attributes: (i) rarity; (ii) extreme impact; and (iii) retrospective predictability. The "black swan" is a metaphor that describes an event that comes as a surprise, has a major effect, and is often inappropriately rationalized after the fact with the benefit of hindsight. Taleb (2010) argues that this phenomenon is accelerating as the world is getting more complicated. Globally, natural and made-made hazards are occurring at an increasing rate.

Borodzicz (2005, pp. 81-82) argues that a disaster is an irreparable situation caused by failing to manage a number of ongoing emergencies and crises. It has overwhelming end results in terms of loss of life, infrastructure and finances, leaving an indelible effect on the organization. The United Nations Office for Disaster Risk Reduction in February 2017 adopted a formal definition of disaster that stated it is "A serious disruption of the functioning of a community or a society at any scale due to hazardous events interacting with conditions of exposure, vulnerability and capacity, leading to one or more of the following: human, material, economic and environmental losses and impacts" (UN General Assembly 2016). In the past, theorists have highlighted that major man-made disasters which occurred within organizations were the outcome of systematic failures due to human, procedural and technical mistakes in the application of operational systems-so-called socio-technical 
disasters (Bowonder 1987, pp. 176-180, Cox and Tait 1991, p. 93, Shrivastava et al. 1988, pp. 285-288, Toft and Reynolds 1994, p. 3, Turner 1994, pp. 215-219). More recently, some scholars have shown that more often the line which divides causes of socio-technical and natural disasters is increasingly thin: those which were once called "acts of God," such as floods, landslides and desertification, are nowadays progressively more attributable to human actions (Gupta et al. 2016, Weichselgartner 2001, pp. 85-86, Wells et al. 2000, p. 497).

There is anecdotal evidence that the impact of disasters can be significantly reduced through investment in development activities that address the root causes of vulnerability and embrace learning from experience (Goldschmidt and Kumar 2016). However, learning from rare and high severity events like disasters challenges the objective of learning through experience (March 1991). Hence the inability to interpret and subsequently learn from such rare events becomes a major challenge for organizations. Such problems can be overcome if a "rich" and systematic approach to disaster interpretation is provided (Beck and Plowman 2009). Gaining robust experience in disaster management helps administrators in humanitarian organizations to take important decisions and effectively establish rescue strategies (Gupta et al. 2016).

For humanitarian disasters, the complexity that arises due to interactions between stakeholders, differing perceptions, lack of commonality in supporting approaches and the maturity of the disaster response mechanism that can often also be seen to add to challenges faced by responders and potentially hinder learning from such events.

Organizations can effectively learn from limited disaster experience in three specific ways. Firstly, they can learn more and different aspects of the disaster as it occurs through effective information-sharing policies, or learn as it happens (Altay and Pal 2014). Secondly, organizations can learn by exchanging different interpretations of what has happened to create a mosaic of conflicting lessons. Both of these exchanges seek to develop a clearer shared understanding of what has occurred, how it is evolving, and the effect of the response. Thirdly, learning occurs when we increase the variety of the multiple perceptions and preferences of outcomes.

Learning from disaster, as a discipline, still has far to go (Sanchez and Mitchell 2017, p. 200), as evidenced by both the frequency and severity of recent events. As Bowker and Chambers (2015) identify in their study of mining failures from 1910 to 2010, 55\% of all catastrophic ("very serious") failures in the last 100 years have occurred since 1990, and $74 \%$ of all failure events post-2000 are "serious" or "very serious." This is not exclusive to the mining industry, of course, and serves to highlight the importance of further research in this area.

The causal factors for disasters are difficult to assess due to the challenging complexity involved. The need for complexity analysis is argued by Komljenovic et al. (2016). Such rare events that usually happen as a surprise (the "black swan") due to one's knowledge/ beliefs can be categorized as (i) unknown unknowns (events that are completely unknown to the decisionmakers); (ii) unknown knowns (analysts do not have knowledge about the specific issue, but others do); and (iii) events that are on the list of known events, but judged to have a negligible probability of occurrence and thus are not believed to occur.

In this study, we propose a model that facilitates learning from rare events. In particular, we show how a set of hybrid tools used for the analysis of similar events can lead to a deeper and varied interpretation, hence extending the learning gained from rare yet severe events. Such richness in learning has been addressed by Beck and Plowman (2009), who argue that middle managers can actively take a role in the interpretation of rare and unusual events. They also provide a temporal model of different stages of interpretation and include relevant types of cognitive bias at each stage of interpretation.

This study will initially explore previous research in a bid to define how disasters differ from failures, to ascertain the key risks that disasters are based upon, and to understand whether and how organizations are able to learn from disasters. Furthermore, the concept of learning from failure and two analysis techniques will be described. Two disasters caused by human actions will be presented and analyzed using the two risk and failure models previously introduced; lessons learned and not learned will be drawn to the attention of the reader.

\section{Previous Research}

In this section, we trace the theoretical developments that relate to our investigation. We start by summarizing the relevant literature on humanitarian operations management (HOM), outlining the evolution of the socio-technical disaster lifecycle and, in particular, its relationship with humanitarian operations, using a supply chain resilience theoretical lens. We then outline theories of organizational learning (and unlearning) from disasters and the impact on humanitarian operations. This will help to theorize the role of middle managers in humanitarian operations, which is the main focus of our paper.

\subsection{Humanitarian Operations Management}

The pioneer of social-technical disaster studies was Barry Turner. In 1978, he proposed a model in six 
stages to understand systematic failure within organizations (Turner 1978). A crisis or disaster, according to Turner, begins with the incubation of an issue that has been ignored, misunderstood or mismanaged, resulting in escalation to the next stage and then to the next, if the same errors and omissions in response are repeated, culminating in disaster. Disasters have an overwhelming impact not only on developing countries, but wherever they occur. Hurricane Harvey, for instance, flooded Houston in 2017 with more than four feet of rainfall, causing floods that were unprecedented, showing the lack of preparedness and response capability in one of the most powerful countries in the world. It is hard to predict accurately where or when a disaster could occur and which areas are at high risk after disruptions (Peck 2006). The efficiency of disaster relief operations relies on organizations' ability to know exactly where disaster conditions exist and to plan the capacity to get medical procedures and relief supplies to the scene of trouble in the shortest time (Scholten et al. 2014).

Understanding the nature of the humanitarian operations helps to develop an effective response to, and recovery from, crisis disruption (Sodhi and Tang 2014). Humanitarian operations have unique characteristics due to the large-scale devastation after a disaster, the extremely tight lead time, and the unusual constraints on humanitarian resources and logistics capabilities. Moreover, factors such as a lack of data (Eftekhar et al. 2017), high variation in stakeholders' interests (Ergun et al. 2014), insufficient usage of resources and the absence of customer power (in this case, beneficiaries in need) (Holguin-Veras et al. 2013) add to the complexity of rescue operations post-disaster.

As a result of this complexity, many authors began to test the applicability of the operations and supply chain management (OSCM) models to the humanitarian field despite the significant difference between these two fields (Besiou et al. 2014, Roth et al. 2016). This trend is derived from the book Humanitarian Logistics (Tomasini and Van Wassenhove 2009), where the authors, in their introduction, made a commitment to investigate how OSCM can be mapped across the means and methods of humanitarian planning to improve process efficiency. Charles et al. (2009) responded to the call and modified a framework of enterprise modeling (ISO 19439) to develop a framework of disaster management including four stages: preparedness, immediate response, support and dismantling. Ali et al. (2017) used the supply chain resilience concept to identify three phases of disasters - the pre-disaster, during disaster and post-disaster phases -and five capabilities of disaster management: the abilities to anticipate, to adapt, to respond, to recover and to learn. Gupta et al. (2016), too, have defined three time phases of disasters aligned with those phases of Ali et al. (2017): before, during and after the disaster. Furthermore, the disaster lifecycle has received various definitions in the literature. For instance, the Office of Coordination and Humanitarian Affairs (UN OCHA 2013) focuses on disaster preparedness, response and mitigation capabilities. This is in harmony with O'Brien et al.'s (2010) vision of the disaster management cycle that comprises preparedness, response, recovery and mitigation capabilities.

Despite the key role that disaster preparedness, response, recovery and mitigation play to help communities face the post-disaster devastation and bounce back, limited attention is paid to the capacity of learning from the disaster experience. This gap is pointed out by both Blackhurst et al. (2011) and Jüttner et al. (2007), who assert that research in the disaster management field needs to address the broader role of learning capabilities to build resilience communities. The next section will respond to this gap and present a review of the theories of learning from disasters.

\subsection{Theories of Learning from Disasters}

How do we learn about learning from failures? Researchers have stated different theories. Desai (2010, pp. 715-716) highlights the magnitude by which catastrophic failures encourage organizations to learn from those events when presented through reported case studies. However, Labib (2014, p. 11) provides a taxonomy of theories related to learning from disasters in the form of a list of contrasting dualities. Citing Taleb (2010), he argues that whoever presents a reported case study must be aware of narrative fallacy. In terms of risk analysis and risk perception, Reason (1997, p. 9) proposes the wellknown "Swiss cheese model" theory. Adding to this, Kahneman (2012, p. 204) states that "the reward to irresponsible risk-seekers" could be seen as slices with too many holes or a lack of cheese slices; conversely, too many slices or slices with no holes can be associated with adverse risk (Labib 2014, p. 12).

Two traditional schools of thought regarding organizational learning should be mentioned: normal accident theory (NAT) and high reliability organizations (HRO). The first, proposed by Perrow (1984, pp. 5-11), claims that the unpredictability of accidents is due to the complexity of modern systems and their interconnectedness; thus the inevitability of failures is built in. In contrast, the second theory (Rochlin et al. 1987) shows how organizations can successfully prevent accidents when they continuously adopt high standards of safe culture in complex systems, redundancy, dynamic decision-making and flexibility to learn. Considering this, Labib (2014, pp. 13-15) proposes an overall balanced approach, citing Pidgeon (1991), who addressed four theories related to the safety culture: the paradox of safety as an incubator for hazards; risk due to 
incompetence; a cultural background of risk acceptance; and critical issues on learning from failures.

However, in the 1990s, theorists were inclined to give more emphasis to learning from successes than from failures (Kim and Miner 2000, pp. 708-710; McGrath 1999, pp. 16-20, Sitkin 1992, pp. 233-243). This view gained limited acceptance, and the focus on the benefit from learning from failure was restored. At the start of the 21st century, several scholars not only reinforced the significant concept of learning from failure which occurred in the same organization, but also started to investigate whether one could learn from failures which happened in other organizations (Carroll et al. 2002, pp. 117-129, Chuang and Baum 2003, pp. 38-41, Denrell 2003, pp. 227-230, Desai 2008, pp. 594-596, Haunschild and Rhee 2004, pp. 1545-1549, 1556, Haunschild and Sullivan 2002, pp. 609-613). This built on the initial isomorphic learning theory proposed by Toft and Reynolds (1994).

Kim and Miner (2007, pp. 687-689) and Madsen (2009, pp. 872-873) proved that organizations can learn more from failure than success and can exploit what they have gleaned from near failures. However, recent studies have highlighted that organizations do not always capture this. Labib (2014, pp. 3-4) has illustrated through reported cases of disasters how major organizations such as the National American Space Agency (NASA), British Petroleum (BP) and Toyota failed to learn from their failures, as evidenced by the repeated occurrence of disasters in their own organizations.

Learning is not an easy process. Carroll et al. (2002, p. 121) argue that organizational learning is a challenge; it requires us to break mental models and habitual routines which are ingrained within the organizational culture. Recently, different scholars have shown how organizations have been keener to focus on rare events such as disasters and catastrophes, with greater desire to invest in learning how to avoid the recurrence of similar events (Beck and Plowman 2009, pp. 917-921, Christianson et al. 2009, pp. 856-858, Madsen 2009, pp. 872-873, Rerup 2009, pp. 884-891, Starbuck 2009, pp. 929-935, Zollo 2009, pp. 895, 904-906). Based on those studies, Lampel et al. (2009, pp. 838-840) provide two types of impact on organizational learning: potential impact, where they trigger a subsequent process of learning, and potential relevance, where they influence the scale of future capacity to learn within the organization. An overall evaluation is offered by Madsen and Desai (2010, pp. 450-452, 470-472), who state that learning from failure rather than from success offers more circumstances for experimental learning and is directly linked to enhanced performance. Moreover, they argue that previous researchers have been too focused on learning the outcomes of failures rather than researching the process of learning from failures and how to use models to facilitate this. This study fully supports
Madsen and Desai (2010) in their evaluation and again stresses the need for the latter. Indeed, this focus on learning from failure has permeated organizational standards and generated the introduction of the first British Standard in crisis management, BS11200:2014. This explicitly recognizes what the academic literature has found and proposed. Within the standard, the importance of situational awareness and the need to consider what may occur in the future, in part based upon previous events, are clearly stated. Perhaps the most robust acknowledgement of the need to learn from crisis and disaster is seen within Section 8 of the standard. The document highlights the transfer of academic musings as valid and integral inputs into an organization's resilience and an important tool in preparing for and responding to disaster (BS11200:2014).

One of the first researchers to narrow his focus to accidents was Trevor Kletz, who analyzed several case studies and their underlying causes of failure. He states, however, that to use accident models might restrict the free thinking necessary to investigate accidents in a more obvious way (Kletz 2001, pp. 2-3, 7) In this regard, several scholars have adopted hybrid models to enhance flexibility in the presence of a several number of decision factors (Grigoriou et al. 2019, Kou et al. 2014, pp. 95-97, Labib and Read 2015, pp. 7869-7874, Li et al. 2014a, pp. 116-118, Li et al. 2014b, pp. 108-110, Vaidogas and Sakenaite 2010, pp. 391393, Zolfani et al. 2013, p. 89). Moreover, Labib and Read (2013, pp. 397-399) propose an approach to learn from failures, oriented towards process questions, focused on radical learning and based on learning from failure rather than variance questions, control learning and learning from success.

Important practices are also introduced to leverage learning after disasters, including post-disruption knowledge management, knowledge sharing, enabling an environment of trust, seeking out delivery of ideas, and building social capital among the community members, humanitarian teams and volunteers (Figure 1; Ali et al. 2017, Seville et al. 2015). Post-disruption knowledge management cultivates the learning ability in the aftermath of disasters through education

Figure 1 Practices for Organizations to Embrace the Ability to Learn [Color figure can be viewed at wileyonlinelibrary.com]

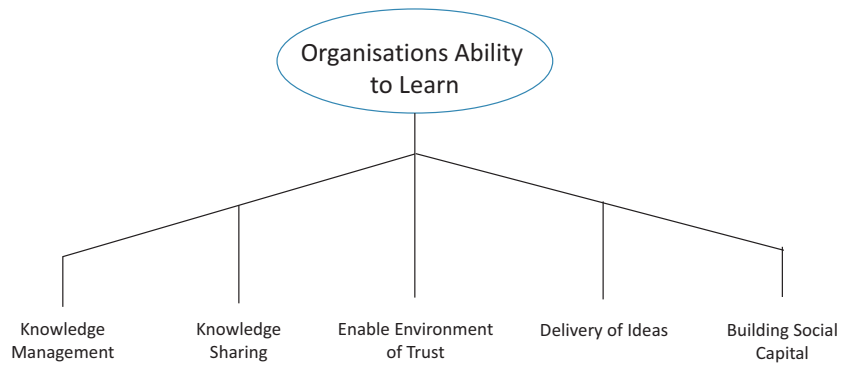


and training (Rice and Caniato 2003), post-disruption feedback, cost/benefit knowledge (Blackhurst et al. 2011), self-reflection and simulation exercises. Humanitarian organizations must also ensure that knowledge sharing is available on an ongoing basis between suppliers, communities and volunteers. In addition, creating a safe "high-trust" environment is critical for these organizations to establish a culture of continuous learning. It encourages all partners to speak up, offer new ideas, support diversity of opinions and encourage innovative solutions. Finally, building social capital across supply chain entities and other community stakeholders, in particular in disaster situations, strengthens partners' ability to learn through interorganizational relationships (Johnson et al. 2013) and relational competence (Wieland 2013).

Although the policy and disaster management literature reports the importance of learning for disaster management agencies, there are still insistent barriers to learning lessons from failure (Macpherson et al. 2010). The same authors divided the barriers of effective post-crisis learning into three categories; cognitive, social, and organizational. While cognitive barriers concern the intellectual biases embedded in the values of the disaster managers that prevent them from capturing the full lessons from disaster events (Torlak 2004), social barriers are often caused by political and psychological factors. Organizational barriers, on the other hand, derive from the unclear relationship between organization's structure and the learning process (Fiol and Lyles 1985). The decentralized structure of organizations facilitates more effective learning post-crisis, as it allows shifts in beliefs and actions when dealing with disasters, as opposed to centralized organizations, which tend to reinforce past behaviour during and after the disaster.

\subsection{Theorizing the Role of Middle Managers in Humanitarian Operations}

In this section, we attempt to theorize the role of middle managers in humanitarian operations. In particular, we address who "middle managers," are and their scope in terms of responsibility in humanitarian operations. It has been suggested that middle managers are in a good position to facilitate both divergence and convergence of interpretations of rare and unusual events (Beck and Plowman 2009), more "richly," using March's (1991) term. Middle managers are those who are able to make decisions about how to implement the strategic objectives. They operate at the intermediate level of the organizational hierarchical structure, normally two or three levels below the CEO. Therefore, they are in a good position - through their interactions with those above them, with those they supervise, and with their peers - to enrich the learning experience, because they are at the intersection of the vertical and horizontal flow of information (Beck and Plowman 2009).

Response time is crucial to mitigate against both prolonged suffering and loss of life in the aftermath of any disaster (Tatham and Christopher 2014). There is therefore a need for managers at both upper and middle levels to encourage and promote approaches which improve the logistic and rapid response to disasters. Hence, it has been suggested (Tatham 2009, Tatham et al. 2017) that advanced technologies such as drones and remotely piloted aircraft systems (RPAS) have the potential to support humanitarian logistical operations. Specifically, such operations may include tasks such as mapping of survivors and casualties, emergency communication, and assessment of environmental conditions, fires and structures. For more details on potential applications, see Tatham et al. (2017). On the other hand, such advanced technologies as drones and RPAS can potentially have an ethical dimension, which may be a concern to middle managers. It has been highlighted (Tatham et al. 2017) that the core concern is mainly related to their association with military applications and their potential to increase the "distance" between the beneficiaries and the aid workers.

Middle managers can be engaged to focus on logistics activities related to needs assessment in terms of assessing the $4 \mathrm{~W}$ question-who wants what, where?-which offers challenges due to the unknown nature of the population demographic, such as old vs. young; male vs. female and so on, of the affected areas (Tatham and Kovács 2010). Such a demand-based mindset by middle managers can lead to a shift in logistics from a push-based to a more effective and efficient pull-based approach (Christopher 2016).

\subsection{Risk Assessment and Modeling Failures}

Aiming to define the difference between learning from a disaster and from a failure, Turner (1994) described a disaster as a situation which forces society to change its patterns due to the magnitude of the catastrophic event, whereas failures might be seen as a collapse of precautions that do not lead to a perceived needed change, and so learning is more difficult (Smith 1990, p. 117). As shown previously, in order to avoid occurrences of failure, organizations should aim to achieve high reliability in processing complex systems. To this end, Weick and Sutcliffe (2011, p. 2) suggest that organizations should continuously seek the following key principles: "track small failures, resist oversimplification and remain sensitive to operations" in the failure anticipation stage, and "maintain capabilities for resilience" and "shift location of expertise" in the containment stage. It is important to remember that organizations are complex sociotechnical systems; hence, all their components should be involved in a proactive risk management (RM) process to maintain high reliability. 
Aiming to support this process, Rasmussen (1997, pp. 186-192) identified the human factor as the decisive cause of failure in $78 \%$ of cases and proposed a model of boundaries not focused on error and violation, but based on systems able to influence human behaviors in their work context. This new approach revealed an updated vision with regard to control of system performance. From this perspective, RM is identified as a control function to contain hazards and operation processes under an overall safe control system.

Models of risk assessment (RA) such as fault tree analysis (FTA), failure mode effect analysis (FMEA) and the risk matrix "as low as reasonably practical" (ALARP), are inspired by the theoretical concept of control system function. They deal with risk of failures through strategies such as avoidance, mitigation, transference, and absorption, and they are usually embedded in a plan-do-check-act (PDCA) cycling system. The FTA is the most significant probabilistic and logic technique used in RA. This is a top-down approach to failure analysis in which causes of a main event are connected in a logical way through "AND" and "OR" gates to minor level events in order to identify all the possible ways in which the main event might occur. The FTA implemented by reliability block diagrams (RBD) becomes an important model of system reliability assessment. The two techniques are complementary: while the FTA highlights the logical causes of failure, the RBD identifies the vulnerable point of the analyzed event. Their best application is found in large-scale failures or disasters, and when they are implemented by numerical probability of occurrence, they can be used to evaluate the likelihood of predictable failures. Moreover, they are ideal advanced tools for learning from previous failures (Labib and Read 2013, p. 399). Therefore, FTA and RBD will be used to facilitate analysis of the two case studies presented in this study in order to identify the generic lessons from those failures.

2.4.1. Introduction to the Techniques Used: FTA Diagrams. The main content of this section is based on Labib (2014, pp. 21-25). One can imagine an FTA as a language with mainly two letters in the form of logic gates, the "OR" and "AND" gates. The gates describe the relationship between the input causes (E1, E2) and the output effect (A), as shown in Figure 2. Note that there are other types of logic gate, but with these two, we can model most problems. The OR-gate indicates that the output event occurs only if one or more of the input events occur. The AND-gate indicates that the output event occurs only if all the input faults occur at the same time. There may be any number of input faults to any of the two gates.

Construction of the fault tree always starts from the TOP event, as shown in Figure 3. Those fault events
Figure 2 The Two Main Logic Gates of the Fault Tree [Color figure can be viewed at wileyonlinelibrary.com]

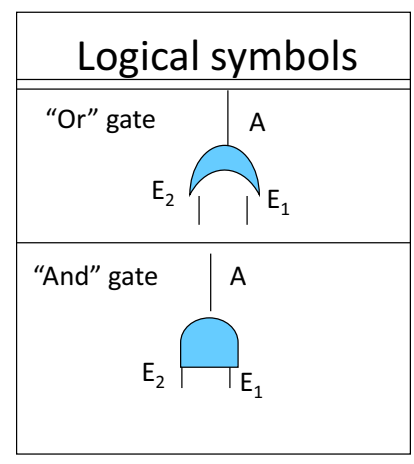

that are immediate, necessary and sufficient causes should be carefully identified and connected to the TOP event through a logic gate. The first level of causes under the TOP event is often referred to as the TOP structure of the fault tree. Then, the construction of the fault tree can be traced level by level, until all fault events have been developed to the prescribed level of resolution. This deductive analysis method is carried out by repeatedly asking, "what are the reasons for this event?"

2.4.2. The Reliability Block Diagram. The RBD is an equivalent diagram based on the construction of the fault tree. Figure 4 shows how to map FTA into an RBD diagram. There are two rules that help to perform such a mapping exercise:

Rule No 1: Every OR-gate in an FTA is equivalent to a series structure in an RBD.

Rule No 2: Every AND-gate in an FTA is equivalent to a parallel structure in an RBD.

Note that one can assess the vulnerability of the system from the RBD, where a general series type structure is vulnerable. Also, vulnerability can be formally assessed using a method called minimum cut sets. In the case of a parallel type structure, this indicates a more resilient system. An example of a parallel structure is to have redundancy, or a back-up system. For more details on how to construct and analyze FTAs and RBDs, as well as their use and limitations, the reader can refer to Labib (2014), Labib and Harris (2015), and Labib and Read (2013).

\section{The Two Case Studies}

In this section, we describe two case studies, the Vajont and Strava dam disasters, which occurred in Italy in 1963 and 1985, respectively. These events were selected to assess whether learning had occurred in the intervening period. They occurred in the same sector, in the same country, and a little over 20 years 
Figure 3 Construction of the Fault Tree

\section{STEPS IN FAULT TREE ANALYSIS ...}

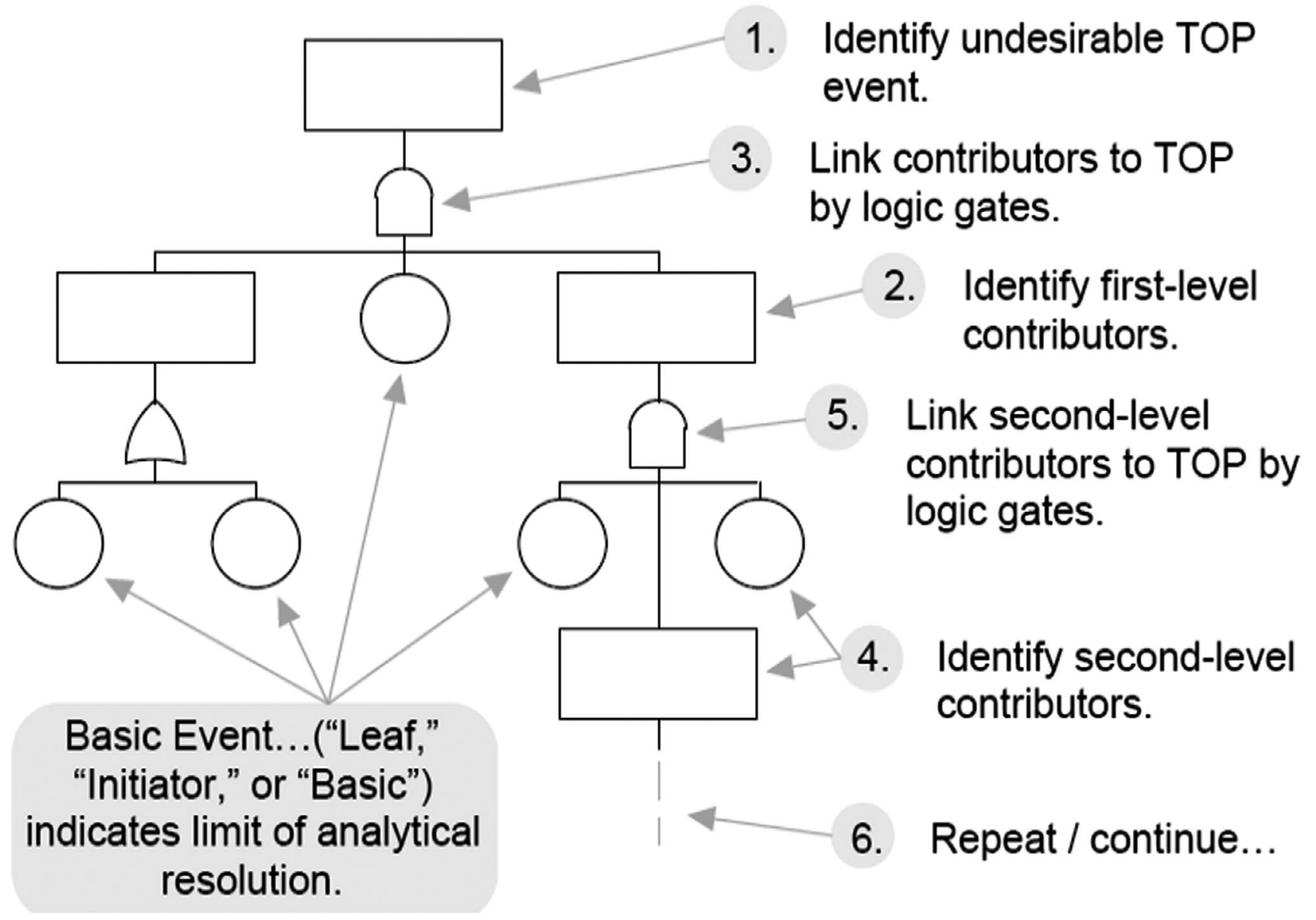

apart. We also attempt to focus our analysis on the role of middle managers in both incidents, using the same analytical hybrid tools in both case studies as way of demonstration.

Note that the two disasters are presented in the form of two case studies based on data available in the public domain, from existing reports or based on related accounts in the literature. Also, in presenting the two case studies, we are aware of the trap of narrative fallacy: when possible, therefore, we attempt to assign a confidence level to the arguments presented, especially if they are not based on factual evidence. We have also attempted to provide a better understanding of causal factors by investigating each case from different perspectives using more than one mental model, or incorporating more than one technique, in the analysis.

\subsection{The Vajont Disaster, Italy, 1963}

At 22:39 on October 9, 1963, a rockslide of about 260 million $\mathrm{m}^{3}$ dashed into the waters of the alpine Vajont Dam, $75 \mathrm{~km}$ north of Venice, Italy. The dam resisted the impact, but the enormous wave of 50 million $\mathrm{m}^{3}$ water generated by the slide, after it had washed away the opposite side of the valley and destroyed two villages located $200 \mathrm{~m}$ above the lake, found its way back to the artificial reservoir. For the second time, the dam resisted the giant wave which engulfed it. At 22:43, a mass of over 25 million $\mathrm{m}^{3}$ of water fell into the valley below the dam and completely destroyed Longarone town (Cadau 2012, p. 45).

The Vajont disaster was the outcome of two congruent factors, human and environmental, where the first triggered the second. In the 1930s, geological surveys revealed a pre-historic rockslide of unknown dimensions leaning on a stable but inclined rock surface, the same surface on which the rockslide occurred on October 9, 1963 (Semenza 2005, p. 34). Even so, the SADE, a nationwide power energy organization, decided to build the dam in that location due to strong economic interest. Between 1960 and 1963, despite a number of failures due to minor slides, small earthquakes and cracks which occurred in the 
Figure 4 Construction of the Equivalent Reliability Block Diagram (RBD) [Color figure can be viewed at wileyonlinelibrary.com]

Fault Tree Analysis (FTA)
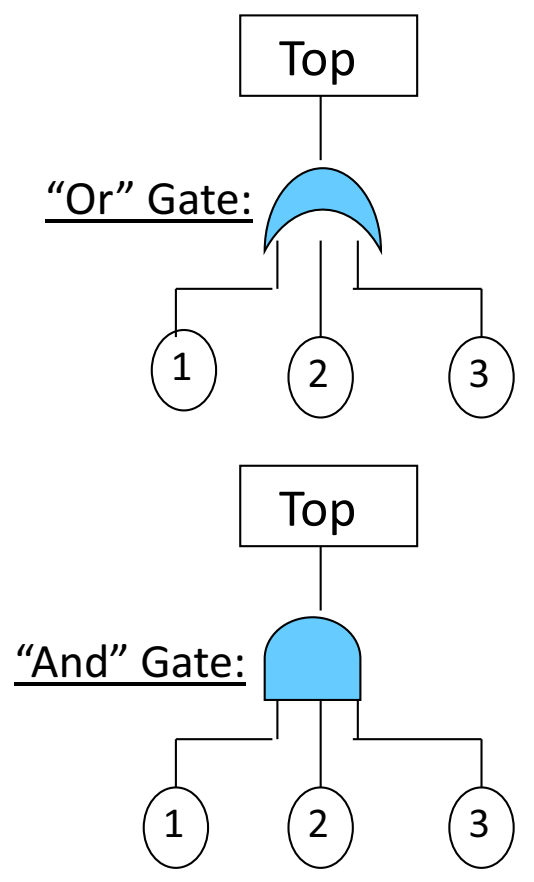

Reliability Block Diagram (RBD)
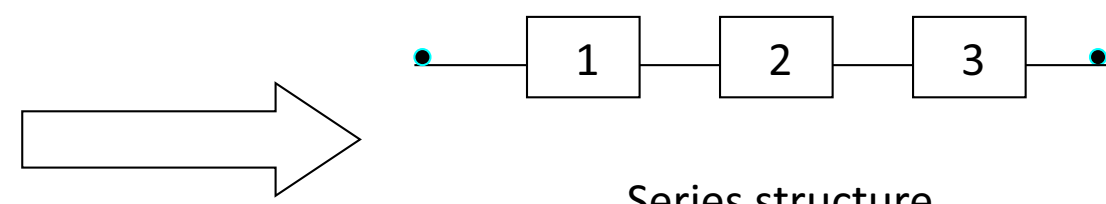

Series structure
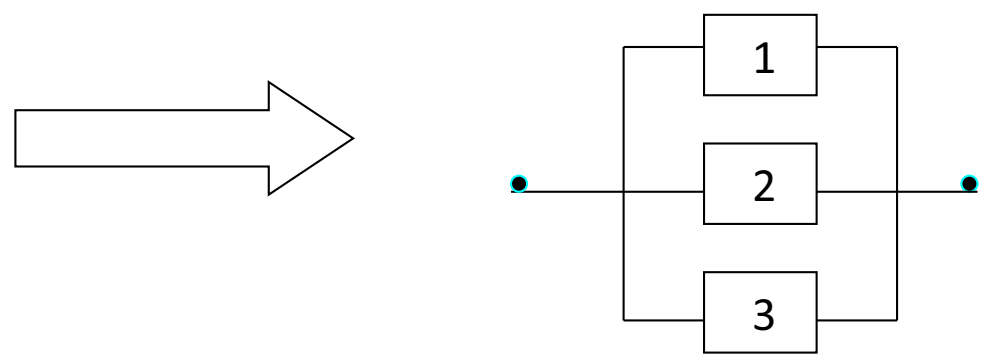

Parallel structure area of the subsequent massive rockslide, and a new geological report which warned of the imminent danger of rock detachment, the SADE administration decided to carry out the reservoir filling test up to the 715 mean sea level (msl) necessary for plant approval, due to a change in ownership from the Italian national energy agency (ENEL). The excessive speed of emptying the lake triggered the definitive Vajont rockslide (Paolini and Vacis 1997, pp. 31-78).

In all, 1910 lives, Longarone town, Erto and Casso villages, and a number of small hamlets and standalone houses were lost. Water and energy supplies and all means of communication were interrupted for several days. The dam cost 3 billion lire to build in 1959 (equal to roughly €1.55 billion in 2017), of which $45 \%$ was financed by the national public. The dam never started to produce energy either before or after the disaster, because where Vajont lake originally stood, now there was a mountain of rock debris (Dagradi et al. 2013).

As shown below in the FTA of the Vajont disaster (Figure 5), there were two main causes: the first was environmental - the rockslide was there before the dam; the second was attributable to human factors - the SADE demonstrated very low reliability. Note here that in our construction of the causal factors in the FTA model, we focus on the human factors, and specifically those that relate to the remit of middle managers, which is the emphasis of our scope of analysis. Despite the redundancy of technical surveys and prioritizing of lucrative aspects, the SADE administration did not take into consideration the suggestion made by two geologists, that even if the enormous entity of the slide was not able to be proved in a mathematical way, they strongly suggested that the dam be built in a different location in the valley and of a reduced size (Semenza 2005, p. 33).

These two pre-construction decisions have equal weight with the other two human factors that caused the subsequent disaster. Firstly, the operative room was warned by the same two geologists not to fill the reservoir above $700 \mathrm{msl}$, and to empty the artificial lake as much as possible in order not to increase the speed of the already unstoppable rockslide. Both bad operative management decisions increased the magnitude of the inevitable catastrophe. Secondly, as can be seen in the RBD (Figure 6), the total absence of a safe culture within the SADE administration created a series of conditions led by the main thought that "it will never happen." Therefore, at the time of the disaster, there was no emergency evacuation in place; nor were emergency services alerted to what was likely to happen. Also, note that the series configuration in terms of factors related to lack of knowledge and lack of safe culture highlights the vulnerability in the system, and the fact that such factors need to be addressed as a matter of priority in order to mitigate 
Figure 5 Fault Tree Analysis Model of the Vajont Disaster [Color figure can be viewed at wileyonlinelibrary.com]

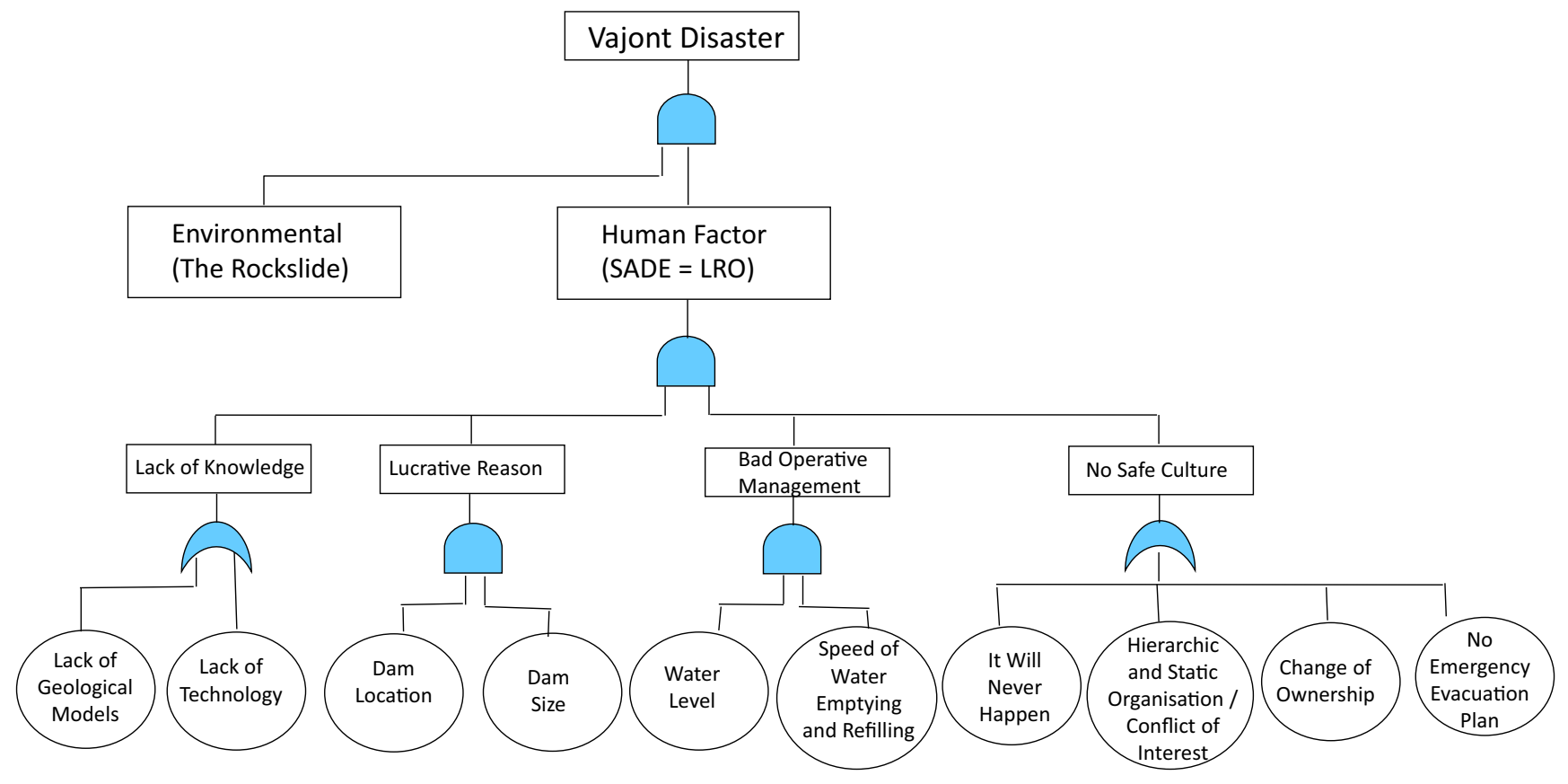

Figure 6 Reliability Block Diagram Model of the Vajont Disaster

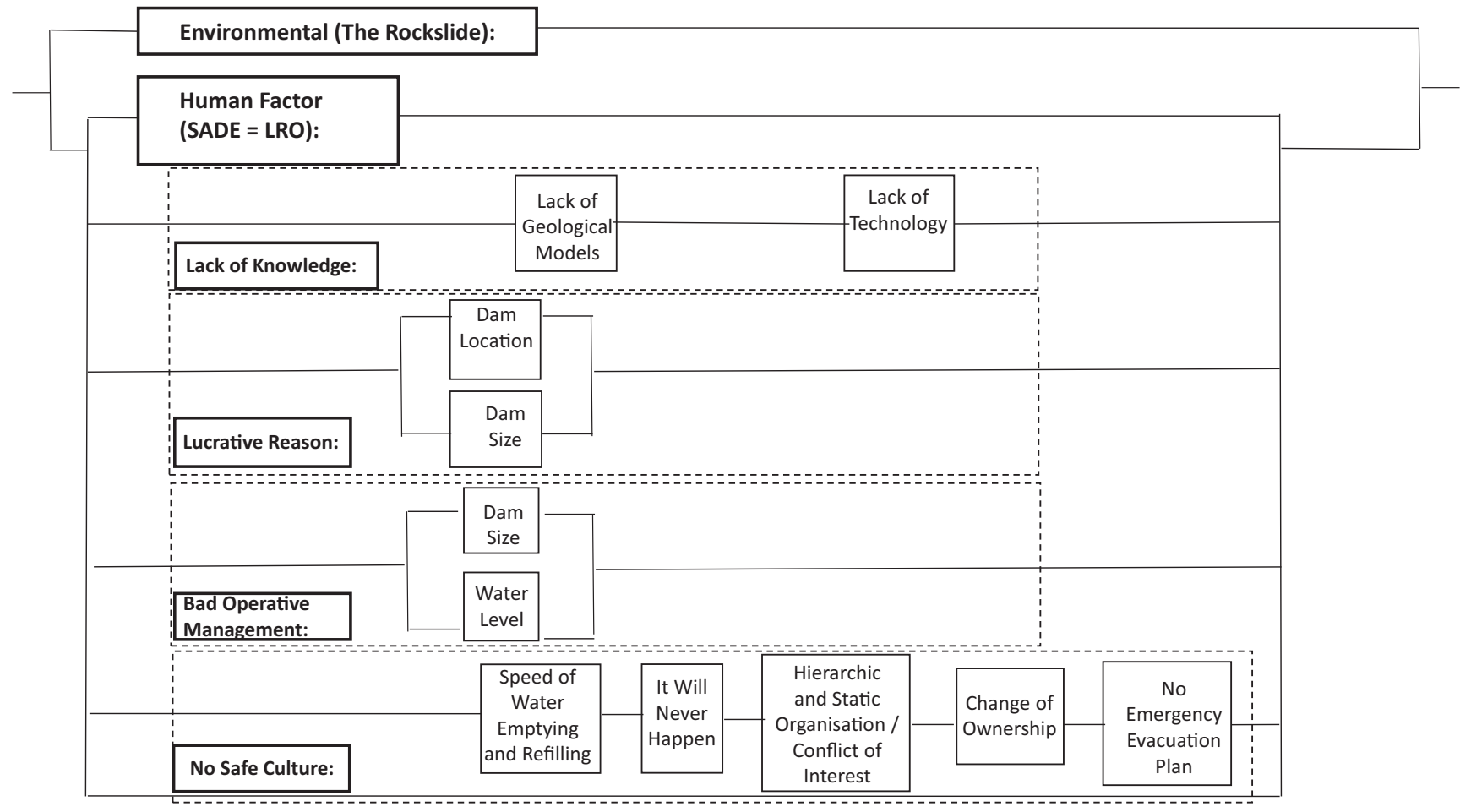

against future incidents. The role of FTA is therefore important to model the relationship between causal factors, and the role of RBD is to identify areas of vulnerability.

Notice here that in constructing the different hierarchical levels of the FTA shown in Figure 5, we can highlight the middle level of the model as a main concern for middle managers.

Using the theoretical lens of Beck and Plowman (2009), which argues that middle managers are in a good position to facilitate richer divergence and convergence of interpretations of rare and unusual 
events, we are able to demonstrate the concerns that are more likely to be affiliated with middle managers. Such concerns, as shown in Figure 5, may include issues related to operative management in terms of allowing water levels to be over $700 \mathrm{msl}$ and the high speed of emptying and refilling. Similarly, issues related to lack of knowledge about geological models or suitable technology may be involved.

\subsection{The Stava Disaster, Italy, 1985}

On July 19, 1985 at 12:22 pm, about $70 \mathrm{~km}$ west of Lake Vajont, two artificial dams at $1400 \mathrm{msl}$, used for the decantation of fluorite extracted from the nearby mines, suddenly collapsed. A wave higher than $10 \mathrm{~m}$ and $180,000 \mathrm{~m}^{3}$ of water, tailings and mud overwhelmed the hamlet of Stava and all the single houses found in its down-valley trajectory at an estimated speed of $90 \mathrm{~km}$ per hour. The mudflow stopped after it had destroyed everything found in its path for $4.2 \mathrm{~km}$ (Sammarco 2004, pp. 91-92).

The two dams were situated on an inclined surface of about $14^{\circ}$ in a Dolomite valley rich with underground springs. They were made by a process known as "upstreaming," well known in the mining industry as one of the less reliable methods inasmuch as the basin is made by the progressive sedimentary deposit of debris resulting from the mining process. The first dam (lower) was used as a base for the second (upper). The lower dam was built without any preventive reinforcement work to reduce the amount of water present underground or derived from rainfall. Furthermore, according to the initial project, the lower dam should have stopped at a height of $9 \mathrm{~m}$, and the upper at $19 \mathrm{~m}$. On July 19, 1985, they were $26 \mathrm{~m}$ and $34 \mathrm{~m}$ high, respectively; the total man-made basin was $60 \mathrm{~m}$ high and contained about $300,000 \mathrm{~m}^{3}$ of water and debris. Moreover, the pressure exerted by the water in the upper dam was excessive, inasmuch as the walls of the dam were built with an inclination of $38 \%$ when $32 \%$ was considered the limit. Finally, there is no indication that any RA was carried out by the staff responsible for the two dams at any time; no structural reinforcement was done; and there were no controls by the technical local authority, which made a site inspection only once, in 1975. (Sammarco 2004, pp. 91-93, Tosatti 2007, pp. 2-4).

According to the reconstruction of events, the upper dam collapsed first into the lower, which failed immediately afterwards. The mudflow killed 268 people and erased an area of $462,000 \mathrm{~m}^{2}$, including 71 building and eight bridges. Not least, in the middle of the tourist summer season, the entire valley was economically penalized by the decreased number of visitors (Tosatti 2007, p. 5).

The FTA of the Stava disaster (Figure 7) shows three main causes: an unusually intense rainfall in the period antecedent to the failure, tailing liquefaction and human factors. What provoked the collapse of the upper dam, though, was the liquefaction of the tailings at its base due to the enormous quantity of

Figure 7 Fault Tree Analysis Model of the Stava Disaster [Color figure can be viewed at wileyonlinelibrary.com]

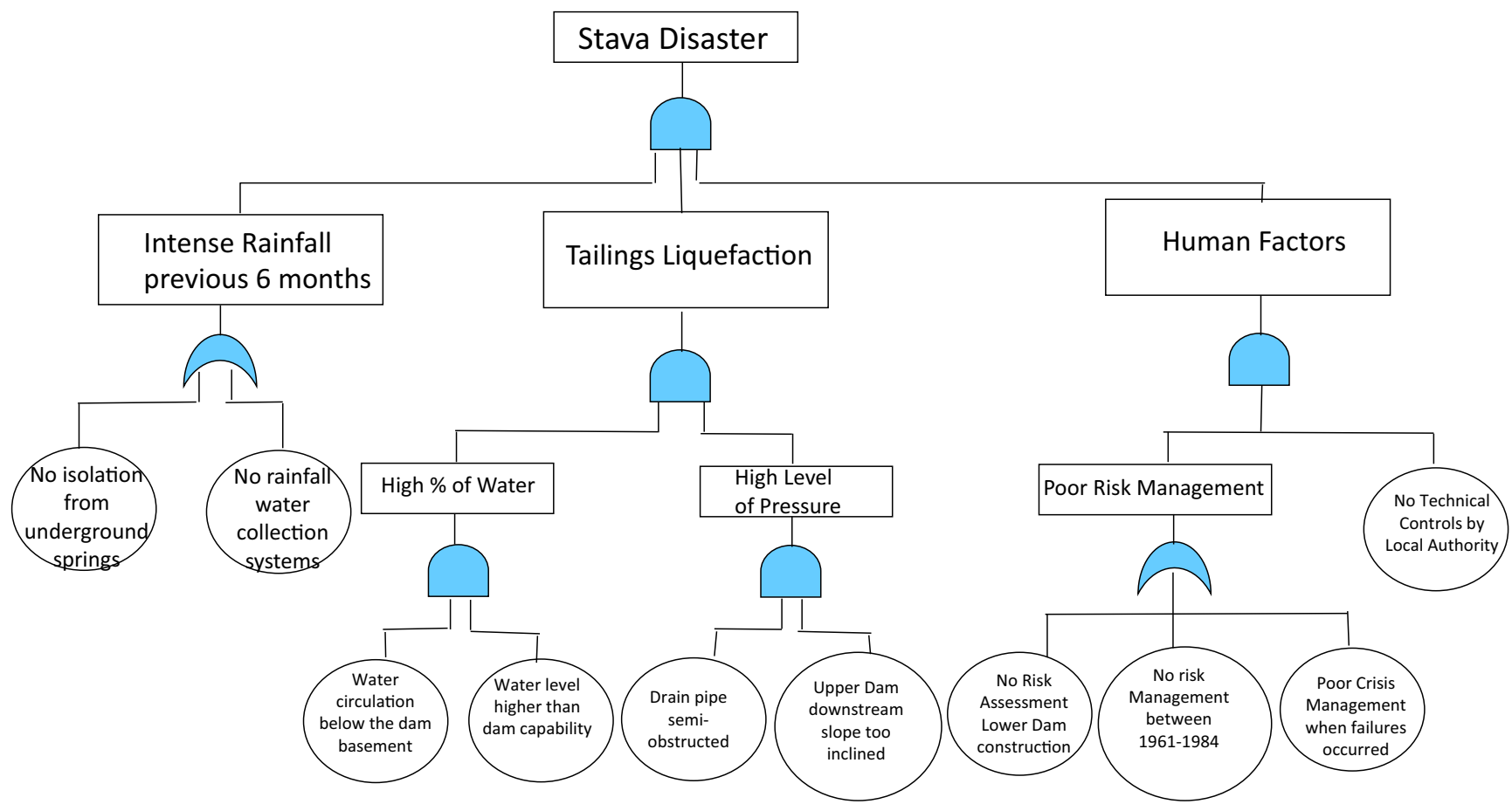


water and the pressure exerted by it. However, the other two factors were equally responsible for the disaster: in fact, the liquefaction could not have happened had the base of both dams not been swamped with water due to the intense precipitation. Furthermore, the total absence of RA drove the appointed staff to operate without controls with regard to the level of water and its percentage in comparison to the tailing, the increasing height and inclination of the wall of the upper dam, and the consequent rising water level and pressure. Again, such issues are the concern of middle managers and, again using the theoretical lens of Beck and Plowman (2009), we can focus on such issues when constructing the FTA model.

Moreover, as can be seen in the RBD (Figure 8), the absence of RM has been highlighted with equal weight to the absence of technical inspection by the local authority. In fact, had those controls been carried out, the rising walls of the upper dam could have been stopped years in advance. The absence of suitable controls by local authorities is a further indication of failure. Again, it should be emphasized here that having a set of boxes arranged in a series configuration in the RBD is attributed to poor risk management, and such vulnerability requires urgent attention with respect to the remit of middle managers. The contributing factors to such poor risk management can be mitigated through more training in these areas, as well as enacting more adequate policies and procedures for risk management.

Finally, in the six months prior to the disaster, two different failures occurred within the same draining pipe in the lower dam, which were not fixed properly. This underlines the superficial approach to the already overall complex situation. Periodic inspections and proper crisis management could have saved 268 lives and the industrial plant.

\section{Generic Lessons from These Failures}

The overarching generic lesson from this work is that in order to have effective and efficient mitigation, it is important to reflect upon the lessons learned and use them. The approach of utilizing the proposed hybrid techniques can facilitate such a learning process. Hence, problem structuring of causal factors and their relationship in the form of a fault tree with emphasis on the role of middle management, coupled with a vulnerability analysis in the form of a block diagram, means that such a hybrid model can act as a mental model that summarizes casual factors and improves resilience.

Within this section, in particular, we focus on two generic lessons that relate to knowledge and complexity in learning from rare events.

The first generic lesson relates to the assessment of existing knowledge. Both disasters were characterized

Figure 8 Reliability Block Diagram Model of the Stava Disaster

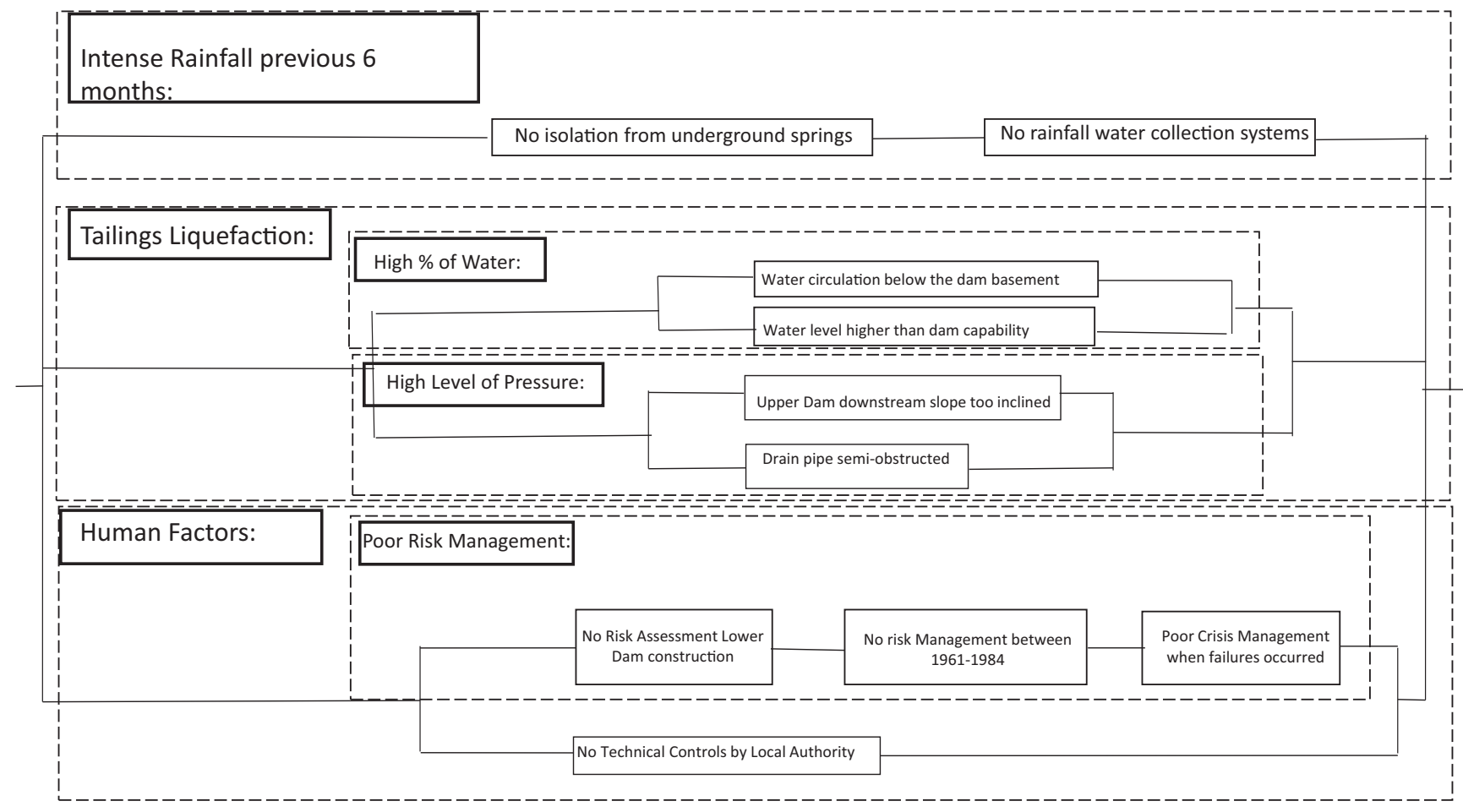


by a non-existent safety culture and a background of a poor level of knowledge by the private organizations coupled with a total absence of controls by the public authorities. In the Vajont case, even if the technology at the time was not sufficient to highlight the real hazard, the SADE always decided on the more lucrative choice rather than putting safety first, which should never be an option. The same could be said about the staff at Stava, but there is no justification for the lack of engineering knowledge.

The second generic lesson relates to understanding the complexity of decision-making within humanitarian operations' logistics. In terms of humanitarian operations, organizations which operate in complex systems due to environmental factors should be aware of the tremendous impact on the surrounding human and natural life which could be caused by their failure. Redundancy in terms of a critical technical approach and a safety culture should always be prioritized in both designing and building any future industrial plant of this magnitude. The national authority in the first case and local engineers in the Stava case did not implement the controls necessary to preserve the safety of the citizens. Moreover, they agreed to build two highly dangerous infrastructures right above inhabited locations; considering the disasters that occurred in these two cases, it is suggested that in the future, the emergence of similar situations will never be allowed. The rigid hierarchy of the SADE administration model and the inadequate management at Stava has highlighted the absolute importance of risk and crisis management. These two significant rules should be addressed by the national authority via a mandatory requirement of all organizations involved in any modification of the environment that could cause hazards for the nearby population.

\section{General Discussion}

Throughout this study, we have emphasized that within humanitarian operations there are three phases: preparedness, response and recovery. However, if one looks at the UN OCHA (2013) disaster lifecycle model, there are in fact four phases, the fourth being mitigation. As mentioned in the previous section, in order to have effective and efficient mitigation, it is important to take the lessons learned and use them. The approach proposed in this study is a way forward with clearly proposed analytical tools.

Although Vajont and Stava involved two completely different organizations, they have been chosen in order to show how low reliability can drive organizations to the occurrence of similar failures, sadly with similarly tragic results. It could be said that these two cases are aligned with Perrow's (1984) normal accident theory, inasmuch as both organizations were operating in a complex system, accentuated by unpredictable environmental changes, which caused the unavoidable failures. This provides a novel learning experience within the HOM paradigm and builds upon the work of Labib and Harris (2015) as stated at the outset of this study. One of the characteristics of HROs highlighted by Rochlin et al. (1987) is the critical ability to learn. It seems fair to say that the managers at Stava did not learn any lessons from the Vajont disaster: indeed, neither organization showed this capacity.

However, when an organization has high reliability and an ability to learn, the theory finds application in practical reality, as can be seen in the case of the Downie slide in British Columbia, Canada. The construction of the Revelstoke Dam and the consequent reservoir were threatened by an enormous pre-historic land slide. Managers of the organization in charge studied the Vajont case and asked for supervision by the geologist Dr Semenza, one of the two geologists who recognized the real threat of the Vajont rockslide in the beginning. Learning came from that failure, and in 1983 massive engineering work was undertaken; the landslide was stabilized and the dam built, which is still functional now (Barrotta 2012, p. 85, Hoek 1991, p. 1485).

\section{Conclusion}

In this study, we have analyzed two case studies and incorporated the use of FTA and RBD tools in order to facilitate the process of identification of causal factors. This was followed by the extraction of a set of recommendations and generic lessons as an outcome of the analysis. Moreover, this study is an attempt to provide a set of tools that can operationalize "rich" learning from rare events, as originally conceptualized by James March (March 1991), and to reiterate the importance of organizational learning from failures.

In terms of future research directions, we propose to extend this work by investigating the second classification of hybrid approaches proposed by Calvin and Labib (2018). Hybrid approaches can be classified in two ways: either through the models and their solution procedures, or through use of the solution procedure of independent types of model. The former option is called the hybrid model, the latter hybrid modeling. In our current approach, we focused on the former option, where an output of one type of modeling can be an input to the other. In future research, one can use hybrid modeling, examining the same disaster using multiple models independently and comparing their findings. This will add richness to our understanding and test whether assumptions 
embedded within each modeling approach can be canceled by other approaches. Another further research direction is to use the high reliability organization framework proposed by Agwu et al. (2019) to assess the maturity levels of those organizations affiliated with humanitarian operations.

\section{References}

Agwu, A. E., A. W. Labib, S. Hadleigh-Dunn. 2019. Disaster prevention through a harmonized framework for high reliability organisations. Saf. Sci. 111: 298-312.

Ali, A., A. Mahfouz, A. Arisha. 2017. Analysing supply chain resilience: Integrating the constructs in a concept mapping framework via a systematic literature review. Supply Chain Manag.: Int. J. 22(1): 16-39.

Altay, N., R. Pal. 2014. Information diffusion among agents: Implications for humanitarian operations. Prod. Oper. Manag. 23(6): 1015-1027.

Barrotta, P. 2012. Il rischio: Aspetti tecnici, sociali, etici. [The Risk: Technical, Social and Ethical Aspects]. Armando Editore, Rome, Italy.

Beck, T. E., D. A. Plowman. 2009. Experiencing rare and unusual events richly: The role of middle managers in animating and guiding organisational interpretation. Organ. Sci. 20(5): 909-924.

Besiou, M., A. J. Pedraza-Martinez, L. N. Van Wassenhove. 2014. Vehicle supply chains in humanitarian operations: Decentralization, operational mix, and earmarked funding. Prod. Oper. Manag. 23(11): 1950-1965.

Blackhurst, J., K. S. Dunn, C. W. Craighead. 2011. An empirically derived framework of global supply resiliency. J. Bus. Log. 32 (4): 374-391.

Borodzicz, E. P. 2005. Risk, Crisis and Security Management. John Wiley and Sons Ltd, Chichester.

Bowker, L. N., D. M. Chambers. 2015. The risk, public liability and economics of tailings storage facility failures. Technical Report, Earthworks, July 21.

Bowonder, B. 1987. The Bhopal accident. Technol. Forecast. Soc. Chang. 32(2): 169-182.

Cadau, M. 2012. Approcci organizzativi all'analisi degli incidenti: Il caso Vajont [Incident analysis organisational approach: The Vajont case]. Bachelor's thesis, Università Ca' Foscari Venezia, Italy.

Calvin, S., A. Labib. 2018. A hybrid model for learning from failures. Expert Syst. Appl. 93: 212-222.

Carroll, J. S., J. W. Rudolph, S. Hatakenaka. 2002. Learning from experience in high-hazard organisations. Res. Organ. Behav. 24: 87-137.

Charles, A., M. Lauras, R. Tomasini. 2009. Learning from previous humanitarian operations, a Business Process Reengineering approach. J. Landgren, B. van de Walle, S. Jul, eds. Proceedings of the 6th International ISCRAM Conference. Gothenburg, Sweden, p. 40.

Christianson, M. K., M. T. Farkas, K. M. Sutcliffe, K. E. Weick. 2009. Learning through rare events: Significant interruptions at the Baltimore and Ohio Railroad Museum. Organ. Sci. 20 (5): 846-860.

Christopher, M. G. 2016. Logistics and Supply Chain Management, 5 th edn. Pearson Education Ltd., Harlow.

Chuang, Y., J. C. Baum. 2003. It's all in the name: Failure-induced learning by multiunit chains. Adm. Sci. Q. 48(1): 33-59.

Cox, S., N. Tait. 1991. Reliability, Safety and Risk Management: An Integrated Approach. Butterworth-Heinemann, London.

Dagradi, C., A. Cristiani, L. Perego, V. Sacchi. 2013. 1963 Vajont 2013. Focus Science Magazine, Mondadori Scienza S.p.A.
Denrell, J. 2003. Vicarious learning, undersampling of failure, and the myths of management. Organ. Sci. 14(3): 227-243.

Desai, V. 2008. Constrained growth: How experience, legitimacy, and age influence risk taking in organisations. Organ. Sci. 19 (4): 594-608.

Desai, V. 2010. Do organisations have to change to learn? Examining the effects of technological change and learning from failures in the natural gas distribution industry. Ind. Corp. Change 19(3): 713-739.

Eftekhar, M., H. Li, L. N. Van Wassenhove, S. Webster. 2017. The role of media exposure on coordination in the humanitarian setting. Prod. Oper. Manag. 26(5): 802-816.

Ergun, O., L. Gui, J. L. Heier Stamm, P. Keskinocak, J. Swann. 2014. Improving humanitarian operations through technology-enabled collaboration in the special issue on humanitarian operations and crisis management. Prod. Oper. Manag. 23 (6): 1002-1014.

Fiol, C. M., M. A. Lyles. 1985. Organizational learning. Acad. Manag. Rev. 10(4): 803-813.

Goldschmidt, K. H., S. Kumar. 2016. Humanitarian operations and crisis/disaster management: A retrospective review of the literature and framework for development. Int. J. Disaster Risk Reduct. 20: 1-13.

Grigoriou, K., A. Labib, S. Hadleigh-Dunn. 2019. Learning from rare events: An analysis of ValuJet Flight 592 and Swissair Flight SR 111 crashes. Eng. Fail. Anal. 96: 311-319.

Gupta, S., M. K. Starr, R. Z. Farahani, N. Matinrad. 2016. Disaster management from a POM perspective: Mapping a new domain. Prod. Oper. Manag. 25(10): 1611-1637.

Haunschild, P. R., M. Rhee. 2004. The role of volition in organisational learning: The case of automotive product recalls. Management Sci. 50(11): 1545-1560.

Haunschild, P. R., B. N. Sullivan. 2002. Learning from complexity: Effects of prior accidents and incidents on airlines' learning. Adm. Sci. Q. 47(4): 609-643.

Hoek, E. 1991. When is a design in rock engineering acceptable? W. Wittke, ed., 7th ISRM Congress. International Society for Rock Mechanics. A.A. Balkema, Rotterdam, 1485-1497.

Holguin-Veras, J., N. Perez, M. Jaller, F. Aros-Vera, L. N. Van Wassenhove. 2013. On the appropriate objective function for post-disaster humanitarian logistics models. J. Oper. Manag. 31(2): 262-280

Johnson, N., D. Elliott, P. Drake. 2013. Exploring the role of social capital in facilitating supply chain resilience. Supply Chain Manag.: Int. J. 18(3): 324-336.

Jüttner, U., M. Christopher, S. Baker. 2007. Demand chain management: Integrating marketing and supply chain management. Ind. Mark. Manage. 36(3): 377-392.

Kahneman, D. 2012. Thinking, Fast and Slow. Penguin, London.

Kim, J., A. S. Miner. 2000. Crash test without dummies: A longitudinal study of interorganisational learning from failure experience in the U.S. commercial banking industry, 1984-1998. Academy of Management Proceedings and Membership Directory, G1-G6.

Kim, J., A. S. Miner. 2007. Vicarious learning from the failures and near-failures of others: Evidence from the U.S. commercial banking industry. Acad. Manag. J. 50(3): 687-714.

Kletz, T. 2001. Learning from Accidents, 3rd edn. Butterworth-Heinemann, Oxford.

Komljenovic, D., M. Gaha, G. Abdul-Nour, C. Langheit, M. Bourgeois. 2016. Risks of extreme and rare events in asset management. Saf. Sci. 88: 129-145.

Kou, G., D. Ergu, Y. Shi. 2014. An integrated expert system for fast disaster assessment. Comput. Oper. Res. (Multiple Criteria Decision Making in Emergency Management) 42: 95-107. 
Labib, A. 2014. Learning from Failures: Decision Analysis of Major Disasters. Elsevier, Oxford, UK.

Labib, A., J. Harris. 2015. Learning how to learn from failures: The Fukushima nuclear disaster. Eng. Fail. Anal. 47: 117-128.

Labib, A., M. Read. 2013. Not just rearranging the deckchairs on the Titanic: Learning from failures through risk and reliability analysis. Saf. Sci. 51: 397-413.

Labib, A., M. Read. 2015. A hybrid model for learning from failures: The Hurricane Katrina disaster. Expert Syst. Appl. 42: 7869-7881.

Lampel, J., J. Shamsie, Z. Shapira. 2009. Experiencing the improbable: Rare events and organisational learning. Organ. Sci. 20 (5): 835-845.

Li, J., Q. Li, C. Liu, S. Ullah Khan, N. Ghani. 2014a. Communitybased collaborative information system for emergency management. Comput. Oper. Res. (Multiple Criteria Decision Making in Emergency Management) 42: 116-124.

Li, J., L. Tang, X. Sun, D. Wu. 2014b. Oil-importing optimal decision considering country risk with extreme events: A multi-objective programming approach. Comput. Oper. Res. 42: $108-115$.

Macpherson, A., D. Elliott, E. Antonacopoulou. 2010. The impact of learning on policy development in response to crisis. Organization Learning Knowledge Capabilities International Conference, Boston, MA, pp. 3-6.

Madsen, P. M. 2009. These lives will not be lost in vain: Organizational learning from disaster in U.S. coalmining. Organ. Sci. 20 (5): 861-875.

Madsen, P. M., V. Desai. 2010. Failing to learn? The effects of failure and success on organisational learning in the global orbital launch vehicle industry. Acad. Manag. J. 53(3): $451-476$.

March, J. G. 1991. Exploration and exploitation in organizational learning. Organ. Sci. 2(1): 71-87.

McGrath, R. G. 1999. Falling forward: Real options reasoning and entrepreneurial failure. Acad. Manag. Rev. 24(1): 13-30.

O'Brien, G., P. O'Keefe, Z. Gadema, J. Swords. 2010. Approaching disaster management through social learning. Disaster Prev. Manag.: Int. J. 19(4): 498-508.

Paolini, M., G. Vacis. 1997. Il racconto del Vajont [The story of Vajont]. Garzanti Editore, Milan, Italy.

Peck, H. 2006. Reconciling supply chain vulnerability, risk and supply chain management. Int. J. Log.: Res. Appl. 9(2): 127-142.

Perrow, C. 1984. Normal Accidents: Living with High-Risk Technologies. Basic, New York, NY.

Pidgeon, N. F. 1991. Safety culture and risk management in organizations. J. Cross Cult. Psychol. 22(1): 129-140.

Rasmussen, J. 1997. Risk management in a dynamic society: A modelling problem. Saf. Sci. 27(2-3): 183-213.

Reason, J. 1997. Managing the Risks of Organisational Accidents. Ashgate Publishing, Aldershot.

Rerup, C. 2009. Attentional triangulation: Learning from unexpected rare crises. Organ. Sci. 20(5): 876-893.

Rice, J. B., F. Caniato. 2003. Building a secure and resilient supply network. Supply Chain Manag. Rev. 7(5): 22-30.

Rochlin, G. I., T. R. La Porte, K. H. Roberts. 1987. The self-designing high-reliability organisation: Aircraft carrier flight operations at sea. Washington: Naval War College Rev. 51(3): 97-113.

Roth, A., J. Singhal, K. Singhal, C. S. Tang. 2016. Knowledge creation and dissemination in operations and supply chain management. Prod. Oper. Manag. 25(9): 1473-1488.
Sammarco, O. 2004. A tragic disaster caused by the failure of tailings dams leads to the formation of the Stava 1985 Foundation. Mine Water Environ. 23(2): 91-95.

Sanchez, L. E., R. Mitchell. 2017. Conceptualizing impact assessment as a learning process. Environ. Impact Assess. Rev. 62: 195-204.

Scholten, K., P. S. Scott, B. Fynes. 2014. Mitigation processes: Antecedents for building supply chain resilience. Supply Chain Manag.: Int. J. 19(2): 211-228.

Semenza, E. 2005. La storia del Vajont. Raccontata dal geologo che ha scoperto la frana. [The story of Vajont. Told by the geologist who discovered the landslide]. K-Flash Editore.

Seville, E., D. Van Opstal, J. Vargo. 2015. A primer in resiliency: Seven principles for managing the unexpected. Global Bus. Organ. Excell. 34(3): 6-18.

Shrivastava, P., I. I. Mitroff, D. Miller, A. Miglani. 1988. Understanding industrial crisis. J. Manage. Stud. 25(4): 285-303.

Sitkin, S. B. 1992. Learning through failure: The strategy of small losses. Res. Organ. Behav. 14: 231-266.

Smith, D. 1990. Beyond contingency planning: Towards a model of crisis management. Ind. Crisis Q. 4(4): 263-275.

Sodhi, M. S., C. S. Tang. 2014. Buttressing supply chains against floods in Asia for humanitarian relief and economic recovery. Prod. Oper. Manag. 23(6): 938-950.

Starbuck, W. H. 2009. Cognitive reactions to rare events: Perceptions, uncertainty, and learning. Organ. Sci. 20(5): 925-937.

Taleb, N. N. 2010. The Black Swan, revised edn. Penguin Books, London .

Tatham, P. H. 2009. An initial investigation into the suitability of the use of unmanned aerial vehicle systems (UAVS) to support the emergency assessment process in rapid onset humanitarian disasters. Int. J. Risk Assess. Manag. 13(1): 60-78.

Tatham, P. H., M. G. Christopher. 2014. An introduction to humanitarian logistics. In M. Christopher, P. Tatham, eds. Humanitarian logistics: Meeting the challenge, 2nd edn. Kogan Page, London, 1-18.

Tatham, P. H., G. Kovács. 2010. The impact of gender on humanitarian logistics. Int. J. Mass Emergencies Disasters 28(2): 148-169.

Tatham, P., C. Ball, Y. Wu, P. Diplas. 2017. Long-endurance remotely piloted aircraft systems (LE-RPAS) support for humanitarian logistic operations: The current position and the proposed way ahead. J. Human. Log. Supply Chain Manag. 7(1): 2-25.

Toft, B., S. Reynolds. 1994. Learning from Disasters: A Management Approach. Butterworth-Heinemann, Oxford.

Tomasini, R., L. N. Van Wassenhove. 2009. Humanitarian Logistics. Palgrave and Macmillan, Houndmills, Basingstoke, UK.

Torlak, G. 2004. Learning organizations. J. Econ. Soc. Res. 6(2): 87-116.

Tosatti, G. 2007. La catastrofe della Val di Stava: Cause e responsabilità. [The catastrophe of Val di Stava: Causes and responsibilities]. Geoitalia 20: 1-5.

Turner, B. A. 1978. Man-Made Disasters. Wykeham, London.

Turner, B. A. 1994. Causes of disaster: Sloppy management. Br. J. Manag. 5(3): 215-219.

UN General Assembly. 2016. Report of the open ended intergovernmental working group on indicators and terminology relating to disaster risk reduction, $\mathrm{A} / 71 / 644$.

UN OCHA. 2013. United Nations Office for the Coordination of Humanitarian Affairs: Annual report.

Vaidogas, E. R., J. Sakenaite. 2010. Protecting built property against fire disasters: Multi-attribute decision making 
with respect to fire risk. Int. J. Strategic Property Manag. 14(4): 391-407.

Weichselgartner, J. 2001. Disaster mitigation: The concept of vulnerability revisited. Int. J. Disaster Prev. Manag. 10(2): 85-94.

Weick, K. E., K. M. Sutcliffe. 2011. Managing the Unexpected: Resilient Performance in an Age of Uncertainty, Vol. 8. John Wiley and Sons, New York, NY.

Wells, C., D. Morgan, O. Quick. 2000. Disasters: A challenge for the law. Washburn Law J. 39(3): 496-525.
Wieland, A. 2013. Selecting the right supply chain based on risks. J. Manuf. Technol. Manag. 24(5): 652-668.

Zolfani, S., M. Esfahani, M. Bitarafan, E. Zavadskas, S. Arefi. 2013. Developing a new hybrid MCDM method for selection of the optimal alternative of mechanical longitudinal ventilation of tunnel pollutants during automobile accidents. Transport 28 (1): 89-96.

Zollo, M. 2009. Superstitious learning with rare strategic decisions: Theory and evidence from corporate acquisitions. Organ. Sci. 20(5): 894-908. 